\title{
Percebendo o ambiente na Lapônia finlandesa ${ }^{1}$
}

\author{
TIM INGOLD
}

TERHI KURTTILA

\section{Sobre o significado de conhecimento tradicional}

Num artigo recente, o antropólogo Bjorn Bjerkli relata sua pesquisa sobre o modo tradicional de uso de terras comunais entre um grupo de agricultores, majoritariamente falantes Sami, que habitam um pequeno vale não longe da cidade de Tromso, no norte da Noruega (Bjerkli, 1996). Bjerkli está preocupado porque este padrão colocou recentemente os Sami em conflito com o Estado norueguês, que afirma que eles não têm o direito de usar a terra da forma como o fazem. O caso está prestes a ser julgado. A dificuldade é que, para justificar legalmente o pleito de usar a terra como um bem comum, o grupo local ${ }^{2}$ terá que demonstrar que este uso está sujeito, desde tempos imemoriais, a regras e procedimentos claros (mesmo se não escritos). Até agora, os Sami foram incapazes de fazer isso, apenas apresentando afirmações muito vagas sobre "a forma como fazemos as coisas aqui". Eles podem falar sobre o que ocorreu no passado, sobre pessoas e eventos, bons e maus anos, entre outras coisas. Mas não são capazes de formular princípios explícitos do uso "tradicional” da terra. Bjerkli está consternado porque

1 N.T.: Artigo originalmente publicado na revista Body \& Society 6(3-4): 183-196 (Sage, 2000). Após mais de quinze anos de sua publicação, alguns comentários dos autores sobre a contemporaneidade dos fatos etnográficos relatados podem causar algum estranhamento. Contudo, considerando que as ideias expostas no artigo são sua maior fonte de interesse, optou-se por manter o texto tal como originalmente publicado, sem adicionar notas explicativas ou observações além das estritamente necessárias.

2 N.T.: O termo "local people" é utilizado pelos autores ao longo de todo o artigo. A opção pelo termo "grupos locais" para sua tradução quis preservar a discussão que os autores fazem da ideia de local como lugar que se constitui reciprocamente com seus habitantes; como grupos que habitam a terra em que vivem, como é o caso dos Sami. São noções diametralmente opostas à de ocupar um espaço, que está mais próxima de uma abordagem geográfica stricto sensu. As pessoas, como dizem os autores, são locais não porque vivem num determinado ponto passível de ser georreferenciado, mas sim porque criam lugares, pertencendo a eles "tanto quanto estes pertencem a elas". 
se os Sami forem forçados a enunciar estes princípios para ganhar o seu pleito pela terra, então no futuro será deles exigido que regulem seu uso da terra de acordo com estes princípios. E o efeito desta regulamentação do Estado poderia ser a destruição da própria tradição que buscam manter.

O cerne do problema repousa no conceito de "tradição", do qual advogados, burocratas e políticos fazem uso tão frequentemente quanto os grupos locais. Está claro que eles querem dizer coisas diferentes com "tradição". Neste artigo, nós sugerimos quais seriam algumas dessas diferenças. Primeiro, contudo, é necessário refletir um pouco sobre a nossa própria prática acadêmica. Pois, em grande parte da discussão na antropologia e disciplinas relacionadas sobre o chamado "conhecimento tradicional do meio ambiente", o sentido no qual o conceito de tradição é utilizado está mais próximo daquele adotado pela administração estatal do que daquele compreendido pelos próprios grupos locais. Uma solução poderia ser abandonar completamente o conceito de tradição: considerá-lo já tão contaminado por sua oposição à modernidade, como que fixado no tempo e desprovido de qualquer sentido histórico, que poderia apenas fornecer uma visão distorcida sobre a vida real das pessoas ${ }^{3}$. Mas esta solução não é nem um pouco satisfatória numa situação na qual os grupos locais valorizam e querem continuar com o que eles mesmos veem como uma forma de vida tradicional. Por outro lado, esta "tradição" é considerada um ingrediente essencial no manejo de assuntos locais pelas autoridades administrativas. Uma solução melhor, pensamos, seria encontrar uma forma de falar sobre tradição que soe mais consonante com as sensibilidades locais, e reconstruir nossa teoria sobre "conhecimento ecológico tradicional" em torno disso. No que se segue, faremos algumas tentativas nesta direção.

Nosso principal objetivo é estabelecer um contraste entre dois entendimentos acerca do conhecimento tradicional: o primeiro envolvido pela lógica do Estado e o segundo pelas práticas cotidianas das pessoas. Para simplificar, nós os denominaremos CTM (conhecimento tradicional produzido pelo discurso da modernidade) e CTL (conhecimento tradicional produzido a partir das práticas locais), respectivamente. Como a forma vaga das expressões colocadas entre parênteses revela, tivemos que escolher nossos termos com algum cuidado. A literatura está repleta de dicotomias de um tipo ou de outro, todas elas pretendendo esboçar o caráter particular do local, do não-Ocidental e do tradicional contra o pano de fundo de uma modernidade Ocidental global uniforme e descaracterizada. Nossa intenção não é propor mais uma oposição deste tipo. É, ao contrário, mostrar que os termos nos quais estas oposições são construídas são fundamentalmente incomensuráveis com a experiência vivida das pessoas com cujos conhecimentos e práticas nos deparamos. Por isso, argumentamos que a construção do "conhecimento indígena" (CTM), por meio de sua oposição à ciência moderna, implica uma ideia do que significa conhecer que desenraiza aquele que conhece, e que isto é incompatível com formas de conhecer (CTL) constitutivas da localidade.

3 É, certamente, a recusa da vida real em permanecer estática e confinada a uma camisa de força que leva à percepção de que a tradição está na iminência de desaparecer a todo instante. 
É importante estar de sobreaviso contra outro possível equívoco em relação à natureza do contraste que estamos esboçando aqui, não menos porque, inicialmente, nós mesmos fomos vítimas dele! Numa versão preliminar deste artigo, nós definimos CTM e CTL, respectivamente, como conhecimento tradicional na "concepção moderna" e na "concepção local". Isto fazia parecer que pessoas educadas na convenção da modernidade Ocidental compartilhavam um conceito de tradição, enquanto grupos locais compartilhavam outra. A tarefa, então, seria a de comparar o "nosso" conceito com o "deles". No entanto, como mostraremos em seguida, a ideia de que a experiência das pessoas é organizada em termos de conceitos compartilhados que são transmitidos através da sua educação numa cultura particular pertence, justamente, ao discurso moderno sobre conhecimento tradicional. Comparar CTM e CTL nesses termos seria confirmar, ao invés de desafiar, a hegemonia deste discurso. Nosso objetivo é outro. Longe de nos engajarmos num exercício anódino de comparação entre culturas, nós começamos por desestabilizar as fundações epistemológicas sobre as quais estas comparações são construídas. Propomos que o significado de tradição, para os grupos locais, não é dado como parte de um "modelo cultural" recebido para a interpretação da experiência, mas é extraído daqueles contextos interativos nos quais as pessoas tornam-se conscientes de sua habilidade particular de conhecer ${ }^{4}$. Esta habilidade tem suas fontes nas próprias atividades de habitar a terra, que constituem, ao mesmo tempo, os lugares e as pessoas como habitantes locais.

Assim, uma das características do CTM é que ele está intimamente ligado àquilo que nós chamamos de "modelo genealógico". Este está baseado na ideia de que as características físicas e identitárias que constituem uma pessoa são recebidas, ao longo de uma ou várias linhas de descendência, dos ancestrais daquela pessoa, e serão então passadas adiante para os seus descendentes. É comumente suposto que estes atributos são de dois tipos, biogenéticos e culturais, o primeiro atravessando gerações junto com componentes da substância corporal, tais como "sangue" ou "genes", os últimos passados adiante através de uma forma até certo ponto análoga de transmissão de regras e representações, codificadas na língua ou noutros veículos simbólicos. Estas regras e representações constituem o que é conhecido, nos termos do modelo genealógico, como "herança cultural”. Entretanto, se a cultura é transmitida ao longo de linhas de descendência, então seus conteúdos essenciais devem poder ser especificados independentemente das circunstâncias ambientais que seus destinatários individuais encontram no curso de suas vidas. Para qualquer pessoa em particular, a aquisição de conhecimento tradicional — por meio de algum processo de enculturação ou aprendizado social - é assumida como tendo lugar independentemente de, e anteriormente a, sua aplicação ou expressão nos contextos concretos de atividade. Esta presunção, que separa a transmissão intergeracional de conhecimento da experiência ambientalmente situada, repousa no coração do modelo genealógico.

4 N.T.: No original: "people become consciously aware of their own particular knowledgeability" (185). Tal como explicado pelo autor em "The Perception of the Environment" (2000: 416), a palavra "knowledgeability" faz parte de uma teoria da aprendizagem que valoriza os processos de "enskilment", quer dizer, entender na e pela prática que o aprender é inseparável do fazer. 
Que a importância deste modelo, e seu impacto, se estende muito além dos confins da antropologia acadêmica, é evidente em grande parte da controvérsia que cerca o estatuto legal e político contemporâneo dos chamados "povos indígenas". De acordo com a Convenção de 1989 da Organização Internacional do Trabalho, povos são considerados indígenas "pelo fato de descenderem de populações que habitavam o país... na época da conquista ou da colonização ou do estabelecimento das atuais fronteiras estatais" (OIT, 1989: Artigo 1.b; ênfase dos autores). Assim, o conhecimento tradicional dos povos indígenas contemporâneos refere-se não a modos atuais de uso da terra, mas a uma era anterior, pré-colonial, quando seus ancestrais eram os únicos habitantes. Transformada em objeto de memória, essa ligação primordial com a terra foi supostamente transferida em uma cadeia ininterrupta de descendência, dos ancestrais para seus descendentes contemporâneos. Alegar, contudo, que o conhecimento tradicional é recebido em sua totalidade dos antecedentes genealógicos, como um legado do passado, equivale a admitir que a experiência presente dos povos ao habitar a terra não tem nenhum papel na sua constituição. Enquanto os elementos da tradição puderem ser passados adiante, como um bastão, de geração a geração, no fundo não faria diferença onde essas pessoas estão, com quem vivem ou o que fazem para viver. Alguém poderia até mesmo ser considerado indígena, pelo critério da descendência, sem jamais ter posto os pés na terra ancestral.

Os princípios do modelo genealógico, contidos na própria definição formal do estatuto indígena, tiveram, desde sempre, consequências catastróficas para as pessoas assim designadas. O Estado geralmente usou deste artificio para justificar suas políticas de remoção das populações tradicionais de seus territórios. Para assegurar a continuidade da valiosa sabedoria tradicional, argumenta-se, nada mais é necessário do que mecanismos institucionais adequados para seu armazenamento e replicação. Assim, os recursos destinados à preservação das culturas indígenas são alocados em museus, no ensino do idioma e do artesanato nativos, na pesquisa folclórica e assim por diante. Para os grupos locais, ao contrário, o seu conhecimento tradicional é inseparável das suas práticas de habitar a terra. E isto porque é nas relações estabelecidas com a terra, seus animais e plantas, que o conhecimento é gerado. Assim, quando os Sami estudados por Bjerkli dizem que sua tradição é "a forma como fazemos as coisas aqui" (Bjerkli, 1996: 9), eles estão se referindo ao conhecimento desenvolvido nas atividades de sobrevivência que fazem da terra - para eles, um lugar. Talvez eles digam que alguém realmente tradicional conhece o país “como a palma de sua mão". Isso, no entanto, não significa que ele carrega este conhecimento na forma de um mapa cognitivo dentro de sua cabeça. Ao invés disso, significa que, por ter crescido ali, ele aprendeu a "conhecê-lo", como um artesão experiente conhece os materiais brutos que constituem sua arte. Isto é, ele é sensível às suas formas e texturas, pode responder criativamente às suas alterações e está sempre alerta às possibilidades que eles comportam - e também aos seus riscos - ao realizar diferentes atividades. Essa é, em resumo, a natureza do CTL. 


\section{Clima e tempo}

Para fornecer uma ilustração concreta do que queremos dizer com CTL, gostaríamos agora de relatar brevemente os resultados de um projeto de pesquisa recente sobre as formas como o povo Sami, que vive no extremo norte da Finlândia, percebe o seu ambiente 5 . Estávamos particularmente interessados em descobrir se, e em que aspectos, o ambiente é percebido como tendo mudado - pelo menos dentro da memória viva - e se estas mudanças poderiam ser associadas ao processo maior de mudança climática, tal como "cientificamente" monitorado e registrado por estações meteorológicas na região. Se tal associação pudesse ser estabelecida, considerávamos, ela nos daria um meio de incorporar o conhecimento local ao processo de modelagem climática regional. E, ao mesmo tempo, teríamos uma base para converter previsões derivadas de modelos de mudança climática em prognósticos localmente significativos para as pessoas. Nossos esforços, contudo, foram frustrados pela constatação, ao longo do projeto, de que cientistas ambientais e os Sami estavam falando sobre coisas bem diferentes. Em poucas palavras, enquanto os cientistas estavam ali para detectar mudanças no clima [climate], o que realmente importava para os Sami eram as mudanças no tempo [weather $]^{6}$. Clima é uma abstração composta por um número de variáveis (temperatura, precipitação, pressão do ar, velocidade do vento etc) que são isoladas para propósitos de medida. Tempo, em contraste, refere-se a sentir calor ou frio, estar encharcado pela chuva, ser apanhado por uma tempestade e assim por diante. Em suma, clima é registrado, tempo é experimentado. E nossas tentativas de integrar registros climáticos e narrativas sobre experiências relativas ao tempo indicaram que a relação entre clima e tempo não é nem um pouco simples.

O trabalho de campo realizado por um de nós (Kurttila) revelou como as experiências do tempo estão intimamente ligadas a histórias de vida individuais: memórias da infância, relatos sobre adversidades enfrentadas, façanhas da época da guerra ${ }^{7}$ e coisas assim. De fato, o material das entrevistas frequentemente revelava mais sobre processos de memória do que sobre episódios climáticos. Quase sempre, observações relativas ao tempo eram tecidas dentro de narrativas sobre o desempenho de tarefas específicas como o pastoreio de renas, a colheita de amoras ou a pescaria, ou sobre eventos dramáticos da vida como o nascimento, doenças ou ferimentos e a morte. Enquanto tais, eles faziam parte do processo contínuo de construção daqueles lugares familiares, junto com seus arredores, que as pessoas chamam de "lar". Entrevistados geralmente achavam difícil recordar como estava o tempo durante períodos em que não estavam em casa (por exemplo, frequentando o internato escolar). Assim, o trabalho

5 O trabalho de campo foi realizado nas três comunidades Sami de Angeli, Lemmenjoki e Karigasniemi por 16 meses, entre maio de 1995 e setembro de 1996.

6 N.T.: A palavra "tempo" foi reservada para traduzir "weather", e não para "time". Para outros trabalhos de Tim Ingold que abordam o conceito de "weather" ver pelo menos: "The eye of the storm: visual perception and the weather" (Visual Studies 20: 97-104, 2005); "Rethinking the animate, re-animating thought" (Ethnos 71: 9-20, 2006); "Earth, sky, wind, and weather" (JRAI 13: S19-S38, 2007); "Footprints through the weather-world: walking, breathing, knowing (JRAI 16: S121-139, 2010); "Landscape or weather-world" (in Being Alive. New York: Routledge, 2011)

7 N.T.: A Lapônia Finlandesa foi palco, durante a Segunda Guerra Mundial, tanto da "Guerra de Inverno" (193940) quanto da "Segunda Guerra Russo-Finlandesa" (1941-44). Foi na retirada das tropas alemãs, contudo, que todos os vilarejos foram queimados durante o que ficou conhecido como "Guerra da Lapônia (1944-5)". 
da memória e, portanto, o senso de continuidade das pessoas em relação a seu próprio passado, estava intimamente ligado à experiência de habitar lugares particulares. Por exemplo, as pessoas mais velhas, avaliando a experiência recente em relação a um passado mais antigo, frequentemente tinham ideias de normalidade das estações que diferiam daquelas da geração mais jovem. Algumas pessoas idosas eram dotadas de habilidade excepcional de ler sinais, no ambiente, de iminentes mudanças no tempo. Mas este conhecimento do tempo não era algo passado adiante como um conjunto de prescrições costumeiras ou fórmulas; em vez disso, ele crescia através da experiência de viver toda uma vida num lugar e de se movimentar por seus arredores.

Nossa pesquisa também revelou uma estreita conexão da maneira pela qual as pessoas percebem o tempo tanto com suas tarefas de trabalho, quanto com seus modos de viajar. Como homens e mulheres estão frequentemente engajados em tarefas diferentes, suas percepções diferem de modo correspondente. Os homens movem-se mais livremente na floresta, pastoreando renas ou caçando, e são sensíveis às formas como o calor e o frio, a chuva e a neve, e especialmente o vento, afetam seus movimentos e os dos seres que vivem na floresta. As mulheres passam mais tempo em casa e estão atentas ao tempo, na medida em que ele impacta as atividades domésticas, o crescimento dos vegetais cultivados, como as batatas, o bem-estar das crianças (assegurando-se que estejam bem agasalhadas) e assim por diante. Há temporadas em que as mulheres também se aventuram na floresta, para colher amoras, mas a experiência do tempo por parte de uma pessoa agachada no solo da floresta é bem diferente daquela de alguém correndo atrás de uma rena! Há também diferenças na percepção do tempo relativas a tarefas executadas por adultos e crianças. $O$ trajeto regular até a escola, hoje normalmente feito em ônibus, se destaca na experiência das crianças. Mas também as brincadeiras, o banho no lago no verão para se refrescar e escapar dos mosquitos, patinar no gelo no inverno e ser capaz de andar de bicicleta numa espessa camada de neve na primavera. "Eu era capaz de ir de bicicleta até a escola em meio à neve”, um homem recordou, "e claro que eu estava sempre atrasado. Era tão divertido que eu antes dava várias voltas lá na floresta”.

Uma vez que a percepção do tempo depende de tarefas e trajetos, as mudanças nas práticas de trabalho e, acima de tudo, na tecnologia de transporte, levaram a novas formas de perceber o tempo. Por exemplo, a adoção do snowmobile nos deslocamentos no inverno demanda uma percepção diferente da profundidade e consistência da neve. No verão, o uso difundido de motos e quadriciclos "crawlers" também afeta a percepção do terreno. Assim como há diferença na percepção da neve sob rodas em relação a sua percepção sob os pés, também a sensação da neve sob o snowmobile é diferente daquela sob os esquis. Particularmente no caso dos deslocamentos com motos para neve, qualquer falha na avaliação correta das condições da superfície do terreno pode colocar em perigo real igualmente a máquina e o motorista, principalmente quando se está viajando sobre gelo coberto de neve. A velocidade dos transportes motorizados aumenta ainda mais o impacto do vento e a severidade da sensação de frio. É claro que a construção da rede de rodovias e as possibilidades de viajar de ônibus ou de carro próprio não apenas permitem um grau e velocidade de mobilidade inimagináveis para as gerações anteriores, mas também isolam o viajante na medida em que a prática de viajar não é mais uma experiência do tempo da forma como costumava ser. Pode-se, por exemplo, ver a geada sem ser ferido por ela, ouvir a 
chuva sem estar nela ou ver o vento nas árvores sem senti-lo em sua face. Portanto, as pessoas começam a perceber o tempo menos através da experiência corporal direta, e mais em termos de como ele afeta o desempenho dos seus veículos. Contudo, como componentes de um terreno limpo e nivelado, artificialmente recortado através de uma paisagem principalmente florestal, as rodovias têm seu próprio tempo, conhecido por todos aqueles cujo meio de vida, de alguma maneira, depende delas. Elas são mais sujeitas a ventos e mais frias no inverno, e mais quentes, secas e poeirentas no verão.

Para os Sami, a percepção do tempo é multissensorial. É tanto auditiva, táctil e olfativa quanto visual: de fato, em circunstâncias normais, estas modalidades sensoriais cooperam tão intimamente que é praticamente impossível separar suas respectivas contribuições para a totalidade da experiência relativa ao tempo. Percebe-se, com efeito, com todo o corpo. Mesmo assim, a audição é especialmente importante, mais do que, provavelmente, todos os demais sentidos. Uma pessoa usa a audição para ouvir o canto dos pássaros, a neve chiando sob seus pés, a crepitação do fogo, vozes humanas, sinos de renas distantes, latidos de cachorros, gelo rachando, trovões etc. Estes não são sons de fundo; eles pontuam o espaço da experiência vivida ao invés de o preencher. Cheiros, por outro lado, realmente tendem a preencher o ar. Algumas pessoas dizem que podem sentir quando o ar está esquentando nos dias frios do inverno, prenunciando a neve, e, claro, a floresta cheira caracteristicamente depois de uma chuva de verão. $\mathrm{O}$ tato vem à tona na sensação do chão sob os pés e do vento na face. $\mathrm{O}$ tempo pode também ser sentido com os olhos: a secura e poeira de um dia quente de verão, ou a força do vento numa geada severa. Enquanto as pessoas usam seus olhos, claro, principalmente para ver coisas, para escolher objetos em seu ambiente, a percepção visual do tempo é sobretudo uma experiência de luz: o brilho da luz do sol ou da lua na neve, as modulações da luz e da sombra provocadas por mudanças na formação das nuvens, o relâmpago numa tempestade, as cores do nascer e do pôr do sol, a transparência da água e do gelo, as cintilantes luzes do norte e assim por diante.

A percepção multissensorial do ambiente que descrevemos acima é a chave para a orientação espacial e a coordenação das atividades. No pastoreio das renas, por exemplo, a sensibilidade aos movimentos do vento, de cervos e de outras pessoas é fundamental. Na avaliação das condições iminentes do tempo, observações do comportamento dos animais, como a chegada ou partida de pássaros migratórios, são especialmente importantes. Em ocasiões nas quais tudo fica silenciosamente em suspenso, como num nevoeiro ou momentos antes de uma tempestade, as pessoas podem sentir-se completamente desorientadas, mesmo num entorno familiar. Muitas pessoas tinham histórias para contar sobre ocasiões como estas, que sempre continham a mesma moral: você nunca pode considerar o ambiente como dado. De uma hora para outra, o lugar mais bem conhecido pode "virar" e tornar-se estranho e hostil, deixando o viajante perdido e perplexo. Ninguém é habilidoso ou conhecedor o suficiente para sentir-se apto a se mover na floresta com total confiança: no que se refere ao tempo, deve-se sempre lidar com um grau de incerteza, e é o reconhecimento desta incerteza que distingue o lenhador verdadeiramente experiente. Acima de tudo, mover-se num ambiente significa "sintonizar" seu próprio movimento em resposta aos movimentos do entorno - outros animais, o vento e assim por diante. Onde nada se move, não existe nada a que responder; por isso o sentimento de desorientação. 
Crucial na experiência do tempo por parte das pessoas do extremo norte é o ciclo das estações. Enquanto um fenômeno do clima, a sazonalidade pode ser registrada na forma de flutuações anuais regulares na temperatura, precipitação e horas de luz diárias, sem considerar a vida das plantas, animais e seres humanos. Mas, enquanto um fenômeno do tempo, a sazonalidade é inerente às relações entre ritmos concorrentes de crescimento e movimento de plantas e animais, e da vida social humana ${ }^{8}$. Aqui, por exemplo, estão as imagens evocadas por um pastor de renas Sami sobre a transição do verão, através do outono, para o inverno:

Em agosto a escuridão chega como um ladrão, ela te assalta em poucas semanas, as noites tornam-se mais frescas subitamente - todo mundo estava esperando por isso, mas ninguém estava pronto para isso. Os pássaros estão partindo, desaparecendo com seus gritos através do céu. Pessoas estão colhendo amoras e pescando, tentando continuar com o verão até que tenham que desistir. A natureza está cheia de cores vermelhas e amarelas, as manhãs são frias e luminosas, e é um tempo em que as coisas morrem. Começa a caça de pássaros e alces, renas domésticas são mortas e existe a carne de renas frescas para comer. Por um tempo existem noites escuras e chuva fria, mas não por muito tempo, pois de repente percebe-se que há uma estação pela qual esperar, uma estação de neve e gelo. Todo mundo fala da primeira neve, e o primeiro gelo, e coloca uma marca no seu calendário. Renas estão retornando às suas pastagens de inverno: é inverno novamente, noites escuras, estrelas, lua e aurora boreal- céus com todas as cores. Hora de voltar ao trabalho com as renas.

Esta passagem revela belamente como as variações sazonais são experimentadas como a interação, num contraponto complexo, de mudanças harmônicas de luz, escuridão e cor, de congelamento e descongelamento, de ciclos de vida e morte, dos movimentos migratórios dos pássaros e das atividades humanas de produção (coleta de amoras, pesca, caça, pastoreio) e de consumo (do alimentar-se de peixe ao alimentar-se de carne). E mostra também como toda mudança de estação encarna uma mistura de antecipação e surpresa. Você sabe que o outono está chegando, mas ainda tenta manter-se no verão até o final. E a chegada do inverno sempre o surpreende, não importa o quanto já era esperada.

É coerente com esta compreensão da sazonalidade como um sistema de inter-relações periódicas que, ao recontar suas mais memoráveis experiências do tempo, as pessoas tendessem a se concentrar nos deslocamentos periódicos e nas conjunções anômalas que eles propiciavam. Por exemplo: num ano excepcional, em que a cobertura de neve persistiu até o meio do verão, um entrevistado lembrou a estranheza de ouvir o canto do cuco no meio da neve. Em outro ano, as pessoas relembraram que nevou em julho e a visão de enxames de silhuetas de mosquitos pretos contra o fundo branco. E quando determinados pássaros migratórios se atrasaram para chegar na primavera e no verão, sua ausência pôde ser observada. Contudo, existe um sentimento disseminado de que as divisões anteriormente tão marcadas entre as estações estão desaparecendo. Concomitantemente, as pessoas admitem que estão perdendo suas habilidades de "ler a natureza" e os indícios de mudanças do tempo, e estão confiando mais nas previsões do rádio e da televisão. Isto não é simplesmente uma questão de substituir a forma

8 Esta abordagem da sazonalidade foi desenvolvida por Harris (1998) na sua análise dos ritmos de vida em comunidades ribeirinhas na várzea amazônica. 
"tradicional" de previsão por uma "moderna". Tradicionalmente, conhecer como o tempo agiria era uma questão de observar e responder a sinais sutis de "aviso prévio" no ambiente. O que as previsões oferecem, em contraste, é um tipo diferente de predição: uma projeção hipotética de um futuro estado de coisas, sob a forma de um mapa, que tem que ser interpretada à luz de informações específicas da localidade para que possa ser compreendida.

\section{Tradição como processo e como habilidade}

Num artigo recente, Toni Huber e Poul Pedersen contrastaram a meteorologia moderna com o conhecimento tradicional sobre o tempo. Embora sua fonte para este último seja um material etnográfico sobre o Tibet, suas conclusões são similares às do nosso estudo sobre a percepção do tempo entre os Sami. A ciência da meteorologia, eles escrevem, "representa o ambiente como um conjunto global e quantificado de inter-relações", enquanto, de acordo com o preceito e a prática tradicionais tibetanos, o tempo diz respeito a um ambiente entendido como "um sistema local e qualitativo de inter-relações" (Huber e Pedersen, 1997: 590). Mais significativamente, eles mostram como esta última compreensão do ambiente é fundamentalmente incompatível com as representações modernas dos tibetanos tradicionais: guardiões de uma herança cultural antiga fundada num princípio de coexistência harmônica entre a humanidade e a natureza. Os Sami tradicionais têm sido frequentemente descritos da mesma maneira, como convém ao seu status de povo indígena. A própria noção de herança cultural, como um sistema elaborado de representações transmitidas intergeracionalmente, está assentada em um modelo genealógico que separa a aquisição do conhecimento tradicional da experiência ambientalmente situada. Conforme nossa discussão anterior sobre a distinção entre CTL e CTM, supõe-se que este último é composto de itens de conhecimento que são "repassados" como objetos da memória previamente a sua recuperação e aplicação em contextos de prática.

Contudo, tudo o que dissemos sobre a percepção do tempo dos Sami - sua incorporação nas histórias de vida pessoais de habitar um lugar particular, sua dependência de tarefas e modos de viajar, sua qualidade multissensorial, seu papel na orientação espacial e na coordenação de atividades, e sua periodicidade sazonal - contradiz esta separação entre a aquisição de conhecimento e a sua aplicação. O povo Sami menos aplica seu conhecimento na prática que o conhece por meio da sua prática. Assim, o seu conhecimento tradicional relativo ao tempo, consistindo numa sensibilidade aos sinais críticos do ambiente e na compreensão intuitiva do que significam para a condução de suas tarefas práticas, não é de fato passado adiante - não, ao menos, no sentido que o paradigma modernista prevê. Ele é antes continuamente gerado e regenerado nos contextos de engajamento prático das pessoas com componentes significativos do ambiente. Mas este engajamento tem dois lados. Ele pode ser descrito, por um lado, enquanto "como fazemos as coisas aqui" e, por outro lado, enquanto "como nos sentimos fazendo as coisas aqui". Uma descrição do primeiro tipo requer um relato das atividades práticas; uma descrição do segundo tipo requer uma descrição do tempo. Neste sentido, atividades práticas e tempo são dois lados da mesma moeda. A moeda é CTL. 
Fundamentalmente, a distinção entre CTM e CTL depende da diferença entre pensar a tradição como um tipo de substância e pensá-la como um tipo de processo. Elementar para a concepção moderna da pessoa são as metáforas de continente e conteúdo. Equipados por natureza com capacidades universais, os seres humanos são vistos como repositórios para a variável cultural, conteúdo substantivo que especifica o conhecimento tradicional nas suas diversas esferas de aplicação ${ }^{9}$. Concebido como um conteúdo mental substantivo, está na natureza do CTM permanecer o mesmo de geração em geração. Na realidade, claro, isto não acontece, o que é atribuído a "imperfeições" no mecanismo de transmissão — de forma análoga às causas da mutação genética - por meio do qual o conhecimento é passado de um repositório a outro. Algumas coisas podem ser perdidas; outras coisas ganhas; no geral, então, as tradições mudam. O CTL, por contraste, não é cognitivo; ele não está "dentro da cabeça das pessoas", por oposição a "estar lá fora" no ambiente. Ele é antes um processo que está continuamente ocorrendo. Este processo não é outro que o engajamento prático das pessoas com o ambiente. A própria atividade de relembrar, da qual a continuidade da tradição depende, é parte e parcela daquele engajamento. Com efeito, as pessoas recordam na medida em que vivem. Ao fazer isso, elas seguem um "modo de vida", não no sentido de desempenhar um roteiro recebido dos predecessores, mas de literalmente negociar um caminho através do mundo.

Ao seguir este caminho, o importante é que se possa continuar vivendo - que não se caminhe para um beco sem saída, ou que se seja pego num círculo que conduza o viajante à repetição sem fim de viagens idênticas. De fato, "manter o processo acontecendo" pode envolver uma grande parcela de improvisação criativa, tal como manter o seguimento da música numa banda de jazz. O ponto crucial aqui é que, concebida como um processo, a tradição pode ser contínua sem adquirir uma forma fixa. Não há uma oposição no CTL entre continuidade e mudança. A mudança é simplesmente o que observamos se selecionamos, de um processo contínuo, certo número de pontos fixos, separados no tempo histórico. O crescimento de um organismo, por exemplo, é contínuo, mas se comparamos sua aparência em momentos diferentes ele aparecerá como tendo mudado. Da mesma forma, a expansão do CTL é um aspecto do crescimento das pessoas, nos contextos de suas relações umas com as outras e com o ambiente. Apenas porque as pessoas estão fazendo as coisas de modo diferente agora, em comparação com a forma como as faziam em algum momento do passado, não significa que tenha havido uma ruptura com a tradição. $\mathrm{O}$ que realmente quebraria a continuidade, contudo, seria se as pessoas fossem constrangidas a replicar um modelo "tradicional" (sensu CTM) fixo. O efeito seria similar a uma agulha de gramofone presa no sulco de um disco. A música não tocaria mais. Da mesma forma, qualquer tentativa de "tradicionalizar o tradicional", como Bjerkli tão sensivelmente colocou (1996: 18), romperia a continuidade da vida.

Em essência, CTL é um tipo de conhecimento que seria melhor descrito pelo conceito de habilidade [skill]. Para explicar o que queremos dizer com isso, é necessário fazer três afirmações gerais sobre

9 Existe muito debate entre os cientistas cognitivos sobre se há poucos ou muitos repositórios, ou "módulos mentais", por ser humano, e sobre se - ou em que medida - estes repositórios limitam quais conteúdos serão aceitos, mas eu não devo aprofundar-me nestas questões aqui. Ver Hirschfeld e Gelman (1994) para um balanço deste debate. 
habilidade ${ }^{10}$. Em primeiro lugar, habilidades não são propriedades de um determinado corpo individual considerado, de modo objetivo e isolado, como o instrumento primário de uma tradição cognitiva herdada. Elas são antes propriedades do sistema total de relações constituído pela presença do agente num ambiente ricamente estruturado. Assim, o estudo da habilidade demanda uma abordagem ecológica que situe, desde o começo, aquele que a pratica no contexto de um engajamento ativo com os seus arredores. Em segundo lugar, habilidade prática não é apenas a aplicação de uma força externa, mas envolve características de cuidado, avaliação e destreza. Isto implica que o que quer que os praticantes façam às coisas está assentado em um envolvimento ativo, perceptivo, com elas ou, em outras palavras, que eles veem e sentem à medida que trabalham. Em terceiro lugar, habilidades são refratárias à codificação na forma programática de regras e representações. Então, não é por meio da transmissão de qualquer programa que habilidades são aprendidas, mas antes por uma mistura de imitação e improvisação que se dá no âmbito da prática. O que ocorre, na verdade, é que as pessoas desenvolvem sua maneira própria de fazer as coisas, mas em contextos ambientais estruturados pela presença e atividades de seus predecessores.

Seria equivocado então dizer sobre o CTL que ele é "cultural" ao invés de "biológico", ou que está na cabeça e não no corpo. Ele é antes uma propriedade de todo o organismo-pessoa humana, tendo emergido através da história do seu envolvimento num ambiente. Tendo reconhecido isto, é possível compreender a inabilidade dos grupos locais na formulação de seu conhecimento tradicional em algo mais que termos vagos e gerais. Este fato tem sido frequentemente julgado por pessoas de fora, incluindo funcionários e administradores governamentais, como medida de sua inadequação ou inautenticidade. Mas, na realidade, o caráter vago ou alusivo de suas formulações é a própria fonte de sua força. Elas são, na verdade, regras de ouro, orientações muito gerais que podem ser esboçadas como recursos para ação, mas de forma alguma governam o seu desenrolar (Ingold, 1996b: 36-8; Suchman, 1987: 52). Elas não poderiam fazer isso já que o ambiente normal para qualquer prática nunca é o mesmo de um momento para o outro, e a essência da destreza está em estar, contínua e fluentemente, sintonizado com estas variações para responder a elas. Na medida em que os procedimentos estejam precisamente especificados, ou o movimento "pré-programado", a destreza estará comprometida. Em resumo, o caráter impreciso das formulações do CTL é a condição para a precisão dos movimentos dos praticantes-conhecedores.

Gostaríamos de concluir com três questões. A primeira refere-se à constituição da localidade. $\mathrm{O}$ que torna o conhecimento local? O que torna as pessoas do local? Segundo os parâmetros do discurso moderno, o conhecimento é local, ao invés de global, não porque está ligado a um lugar, mas porque está na cabeça das pessoas que vivem em um determinado local. E as pessoas são locais porque vivem em um lugar específico. Não apenas este é fixado dentro de um sistema de coordenadas globais, independentemente da vida das pessoas, como também elas não precisam viver lá para saberem o que sabem. Por isso, a suposição é que o conhecimento seja transmitido por descendência pelos ancestrais, e não que ele surja da experiência de crescer na terra. Argumentamos, ao contrário, que o conhecimento é local porque ele é inerente à atividade de habitar a terra, que realmente cria lugares. E, ao criar lugares,

10 Estes pontos estão explorados mais detalhadamente em Ingold (1996a: 178-9). 
a atividade de habitar também torna as pessoas habitantes desses lugares - as torna locais. As pessoas pertencem às localidades e ambientes nos quais cresceram tanto quanto estes pertencem a elas. Romper os laços entre as pessoas e o lugar seria o mesmo que uma divisão entre herança cultural e ambiente natural, seria lançar a tradição para longe da sua fonte geradora de significado, considerando-a como o vestígio de uma forma de vida ancestral há muito tempo ultrapassada por sua representação como um objeto da memória. O efeito deste deslocamento seria a ruptura da continuidade da tradição e o rompimento da ligação das pessoas com seus passados.

A segunda questão refere-se à constituição de pessoas. Nós mostramos como, no discurso da modernidade, o conhecimento tradicional está ligado a um modelo genealógico no qual toda pessoa é constituída a partir de dois componentes substantivos, respectivamente cultural e biológico (mental e material), transmitidos pelos predecessores. Para compreender o que o conhecimento tradicional significa para o grupo local, contudo, nós temos que o ver como consistindo em certos poderes de percepção e ação, envolvendo disposições e sensibilidades estabelecidas no curso de uma vida de prática e treinamento num ambiente. Aqui a pessoa é concebida não como uma entidade substantiva, mas antes como um locus de crescimento e desenvolvimento num campo de relações. Do mesmo modo, a contribuição que outras pessoas - frequentemente representadas no idioma do parentesco - fazem ao conhecimento de alguém não é algo substantivo, mas sim o propiciar condições nas quais o crescimento possa ocorrer. As pessoas, em resumo, vêm a se constituir não pela transmissão de "coisas" ao longo de linhas de descendência, e contra o pano de fundo da natureza, mas por meio da experiência imediata de participação sensorial com componentes humanos e não-humanos do mundo habitado. E o conhecimento nascido desta experiência, apesar de comumente desqualificado como "intuitivo", deve necessariamente formar a base de qualquer sistema de regulação ou manejo que vier a tratar o meio ambiente como objeto de preocupação.

Como nossa terceira e última questão, retornamos à distinção entre ciência e conhecimento tradicional. Na linguagem da modernidade, esses tipos de conhecimento são radicalmente opostos, como de fato são as disciplinas das ciências naturais e da antropologia cultural. A ciência pretende estudar a natureza como ela realmente é, enquanto supõe-se que a antropologia ilumina os modelos culturais em termos dos quais as pessoas desta ou daquela tradição organizam e interpretam a sua experiência. Esta divisão convencional de trabalho, na qual cientistas estudam a "realidade" da natureza enquanto antropólogos estudam sua construção cultural, a nosso ver, não mais se sustenta. Afinal, o tempo, tal como experimentado pelo povo Sami, não é menos real que o clima registrado pelos cientistas. No seu trabalho, os cientistas engajam-se em certas práticas de observação ambientalmente situadas, tanto quanto o povo local o faz. Em cada caso, o conhecimento surge deste engajamento. Em resumo, a própria ciência é ela mesma uma forma de CTL: ela é tanto tradicional no seu modo de reprodução quanto gerada em práticas de localidade (Turnbull, 1993). Se uma distinção deve ser traçada entre as tradições científica e local, ela está não no status epistemológico do conhecimento, mas na natureza das práticas de habilidade por meio das quais ele é gerado. Trabalhando sob a orientação do povo local, os antropólogos aprendem sobre o meio ambiente através da participação num conjunto de práticas, enquanto os cientistas aprendem sobre ele através da sua participação em outro. O reconhecimento de que tanto 
os antropólogos quanto os cientistas naturais, cada um à sua maneira, estão aprendendo sobre a mesma coisa (o meio ambiente) e não sobre coisas diferentes (cultura, de um lado, natureza, de outro), poderia não apenas abrir linhas de cooperação potencialmente enriquecedoras, mas também permitir a admissão de grupos locais como participantes plenos e iguais no processo de aprendizado.

Tim Ingold é Professor de Antropologia Social na Universidade de Aberdeen e pesquisador da Academia Britânica e Sociedade Real de Edimburgo. Depois de ter lecionado por 25 anos na Universidade de Manchester se mudou para Aberdeen em 1999 para fundar o mais novo Departamento de Antropologia do Reino Unido. Ingold realizou pesquisa de campo com os Sami e Finlandeses na Lapônia e escreve sobre meio ambiente, tecnologia e organização social no circumpolar Norte, opapel dos animais na sociedade humana, ecologia humana e teoria evolutiva na antropologia, biologia e história. Atualmente está escrevendo e lecionando sobre temas que estão na interface da antropologia, arqueologia e arquitetura. Em seu mais novo trabalho, ele explora as relações entre percepção ambiental e habilidade prática. É autor de The Perception of the Environment (2000), Lines (2007), Being Alive (2011), Making (2013) e The Life of Lines (2015).

Terhi Kurtilla concluiu seu mestrado em antropologia social na Universidade de Oulu, na Finlândia, em 1993, e desde então lecionou nas universidades de Oulu e Lapônia (Rovaniemi). Atualmente é professora do Arctic Centre na Universidade da Lapônia. Vive e trabalha com os pastores de rena Sami da comunidade de Kuttura. Seus principais interesses de pesquisa centram-se na natureza, nos animais e nos fenômenos naturais no Ártico. Já trabalbou com temas tão diferentes como enchentes e pastoreio de renas dentro do contexto de mudanças climáticas.

Tradução: Daniel Belik, Mariana Ciavatta Pantoja, Érika Mesquita e Sandra Sales (pesquisadores do Laboratório de Antropologia e Florestas - Aflora, Universidade Federal do Acre/UFAC). 


\section{REFERÊNCIAS BIBLIOGRÁFICAS}

BJERKLI, B. 1996. "Land use, traditionalism and rights". Acta Borealia 13(1): 3-21.

HARRIS, M. 1998. "The rhythm of life on the Amazonian floodplain: seasonality and sociality in a riverine village". Journal of the Royal Anthropological Institute 4(1): 65-82.

HIRSCHFELD, L.A. \& GELMAN, S. A. 1994. “Towards a topography of mind: an introduction to domain specificity”. In: Hirschfeld, L. A. \& Gelman, S. A. (orgs). Mapping the mind: domain specificity in cognition and culture. Cambridge: Cambridge University Press.

HUBER, T. \& PEDERSEN, P. 1997. "Metereological knowledge and environmental ideas in traditional and modern societies: the case of Tibet". Journal of the Royal Anthropological Institute 3(3): 577-98.

ILO (International Labour Organization). 1989. "Indigenous and tribal peoples in independent countries". In: Convention 169. Geneva: ILO.

INGOLD, T. 1996a. "The history and evolution of bodily skills”. Ecological Psychology 8(2): 171-82.

INGOLD, T. 1996b. “The optimal forager and economic man”. In: Descola, P. \& Palsson, G. (orgs).

Nature and Society: anthropological perspectives. London: Routledge.

SUCHMAN, L. 1987. Plans and situated actions: the problem of human-machine communication.

Cambridge: Cambridge University Press.

TURNBULL, D. 1993. "Local knowledge and comparative scientific traditions". Knowledge and Policy 6: 29-54.

RECEBIDO: $10 / 07 / 2018$

APROVADO: $30 / 07 / 2018$ 